\title{
Urodimento
}

REVISTA DE ESTUDOS EM ARTES CÊNICAS

E-ISSN 2358.6958

\section{Fazer teatro sem fazer teatro: Telatralidades e performavirtualidades como rota em tempos pandêmicos}

Júlia Camargos de Paula

Para citar este artigo:

PAULA, Júlia Camargos de. Fazer teatro sem fazer teatro: Telatralidades e performavirtualidades como rota em tempos pandêmicos. Urdimento - Revista de Estudos em Artes Cênicas, Florianópolis, v. 2, n. 41, set. 2021.

do) DOI: http:/dx.doi.org/10.5965/1414573102412021e0117

Este artigo passou pelo Plagiarism Detection Software | iThenticate 


\title{
Fazer teatro sem fazer teatro: Telatralidades e performavirtualidades como rota em tempos pandêmicos
}

\author{
Júlia Camargos de Paula
}

\begin{abstract}
Resumo
Este artigo objetiva compartilhar experiências artístico-pedagógicas vivenciadas no curso técnico em teatro do Centro Interescolar de Cultura, Arte, Linguagens e Tecnologias (Cicalt) realizadas durante o Regime Especial de Atividades Não Presenciais (REANP) instaurado pela Secretaria de Educação de Minas Gerais (SEEMG) como medida protetiva durante a pandemia da Covid-19. As experiências relatadas pautaram-se na noção de performatividade explorada em experimentos cênicos virtuais, gerando telatralidades e performavirtualidades. Refletiu-se sobre a continuidade do ensino e do fazer teatral no contexto pandêmico a partir da construção de antiestruturas que apontam rotas alternativas para as práticas artísticas e educativas.
\end{abstract}

Palavras-chave: Ensino de teatro. Pandemia da Covid-19. Regime Especial de Atividades Não Presenciais (REANP). Performatividade. Antiestrutura.

\section{Making theater without making theater: \\ Telatralities and performavirtualities as a route in pandemic times}

\begin{abstract}
This article aims to share artistic and pedagogical experiences lived in the context of the technical course in theater at the Centro Interescolar de Cultura, Arte, Linguagens e Tecnologias (Cicalt) carried out during the Special Regime of NonPresential Activities established by the Secretary of Education of Minas Gerais as a protective measure during the Covid-19 pandemic. The experiences reported were based on the notion of performativity explored in virtual scenic experiments, generating telatralities and performavirtualities. It was reflected about the continuity of teaching and theatrical practice in the pandemic context from the construction of anti-structures that point to alternative routes for pedagogical artistic practices.
\end{abstract}

Keywords: Theater teaching. Covid-19 pandemic. Special Regime for Non-Presential Activities. Performativity. Anti-structure.

${ }^{1}$ Mestra em Educação pela Universidade Federal de Minas Gerais (UFMG). Graduada em Teatro com habilitação em Licenciatura pela UFMG. Formada no curso técnico profissionalizante em teatro do Teatro Universitário da UFMG. Professora do Curso Técnico em Teatro do Centro Interescolar de Cultura, Arte, Linguagens e Tecnologias - Cicalt / Valores de Minas. juliacamargosdp@gmail.com

(9) http://lattes.cnpq.br/0044886390944612 $\quad$ (iD https://orcid.org/0000-0001-8824-3610 


\section{Hacer teatro sin hacer teatro:}

Telatralidades y performavirtualidades como ruta en tiempos de pandemia

\section{Resumen}

Este artículo tiene como objetivo compartir experiencias artísticas y pedagógicas vividas en el curso técnico en teatro en el Centro Interescolar de Cultura, Arte, Linguagens y Tecnologias (Cicalt) realizado durante el Régimen Especial de Actividades No Presenciales establecido por el Departamento de Educación de Minas Gerais como medida de protección durante la pandemia Covid-19. Las experiencias reportadas se basaron en la noción de performatividad explorada en experimentos escénicos virtuales, generando telatralidades y performavirtualidades. Se reflejó sobre la continuidad de la enseñanza y la práctica teatral en el contexto pandémico a partir de la construcción de antiestructuras que apuntan a rutas alternativas para las prácticas artísticas pedagógicas.

Palabras clave: Enseñanza de teatro. Pandemia de COVID-19. Régimen Especial de Actividades No Presenciales. Performatividad. Antiestructura. 
Já faz mais de um ano que profissionais do teatro têm reinventado o seu fazer devido às medidas protetivas de isolamento social durante a pandemia da Covid-19. A impossibilidade do encontro e do convívio de forma presencial, elementos geralmente observados como essenciais para a prática e o estudo do teatro, obrigou trabalhadoras e trabalhadores dessa classe a se adaptarem aos modelos remotos e virtuais. Diante dessa realidade, artistas, professoras e professores de teatro têm lançado mão de plataformas como YouTube, Zoom e Googlemeet, entre outras, para darem continuidade a seus trabalhos. Considerando e lidando com as dificuldades impostas pelo momento, docentes e discentes do curso técnico em teatro do Centro Interescolar de Cultura, Arte, Linguagens e Tecnologias (Cicalt) também se debruçaram sobre as possibilidades de investigação da linguagem teatral no contexto do isolamento social e por meio das plataformas virtuais.

Aqui, serão compartilhadas algumas experiências artístico-pedagógicas em teatro vivenciadas ao longo de 2020 na instituição supracitada e também reflexões suscitadas a partir dessas práticas. O artigo relata como telatralidades e performavirtualidades foram inventadas como uma espécie de antiestrutura, no âmbito de um curso profissionalizante em teatro, para sobreviver em diferentes sentidos no contexto pandêmico, criando fissuras no fazer teatral, em um modelo de ensino normativo e pré-estabelecido e nas vivências e relações marcadas pelo isolamento social a partir da noção de performatividade.

\section{Notas sobre o Cicalt antes e durante o contexto pandêmico}

O Cicalt é uma instituição de ensino localizada na cidade de Belo Horizonte $(\mathrm{BH})$ que oferece cursos técnicos nas seguintes linguagens artísticas: música, circo, dança, artes visuais e teatro. O Cicalt foi construído sobre as bases do Programa Valores de Minas, criado pelo Governo do Estado de Minas Gerais em 2005, configurando-se como uma iniciativa de ensino de arte atrelado ao desenvolvimento da cidadania e voltada para jovens de camadas populares. Ao longo do tempo, o programa foi ganhando reconhecimento e tornou-se um espaço de referência em $\mathrm{BH}$ no que diz respeito ao ensino de artes e ações voltadas para 
as juventudes.

Segundo Paula (2020), no ano de 2014, o Governo do Estado de Minas Gerais iniciou a transferência do programa da pasta de Cultura para a pasta de Educação, por motivos que, apesar de não explicitados com nitidez, apresentaram indícios de relações com questões orçamentárias, assim, desde 2016, ano em que foi finalizada a transição entre pastas, o antigo programa ganhou os moldes de escola, passando por consideráveis transformações. Isto é, até 2014, o Programa Valores de Minas, com uma administração autônoma, foi viabilizado por meio de iniciativas estaduais de incentivo à cultura e com parcerias de caráter público-privado, porém, com a nova associação à pasta de Educação, a instituição passaria a ter uma redução de sua autonomia devido ao enquadramento às lógicas, regras e formatos a que são submetidas as escolas estaduais (Paula, 2020).

Ainda de acordo com Paula (2020), os períodos de transição vivenciados na instituição foram turbulentos, especialmente marcados pelo posicionamento do corpo discente que, por meio de diferentes manifestações, questionava as mudanças institucionais encaminhadas pelo Governo e exigia a permanência da proposta pedagógica desenvolvida no programa também na nova escola que a partir dali se instauraria. A proposta pedagógica defendida por estudantes estava pautada em valores democráticos e libertários e no ensino da arte associado à formação social e humana, com estímulo ao aprofundamento do pensamento crítico sobre a realidade e incentivo ao desenvolvimento de uma postura cidadã (Paula, 2020). A luta de estudantes também estava relacionada à manutenção das especificidades da instituição como espaço de ensino de artes, pois já que não há outra escola ligada diretamente à Secretaria de Educação de Minas Gerais (SEEMG) que ofereça cursos artísticos², surgiu uma preocupação sobre a capacidade da pasta de absorver as singularidades desse campo de ensino.

Vale mencionar que, no formato de programa, os cursos oferecidos tinham caráter livre, já no formato de escola, a partir de 2020, os cursos passaram a ter caráter exclusivamente técnico - entre 2017 e 2019 foram ofertados cursos nas

${ }^{2}$ Os Conservatórios Estaduais de Música fazem parte da rede de escolas estaduais de Minas Gerais, mas contam com normas específicas para a organização e funcionamento do ensino de música que não se aplicam ao Cicalt. 
duas modalidades em função da transição (Paula, 2020). Isso ocorreu, pois a SEEMG não possui regulamentação e autorização para cursos livres nas escolas estaduais, apenas formações no contexto do ensino infantil, básico e profissionalizante, nesse sentido, o Cicalt precisou adaptar a modalidade dos cursos ofertados.

Pode-se observar, portanto, que a institucionalização do antigo programa como escola traz firmamento enquanto política pública de ensino quando comparado ao modelo anterior, porém, o Cicalt está continuamente resistindo a processos de uniformização buscando reafirmar singularidades da formação artística herdadas do Valores de Minas diante da SEE-MG, especialmente por meio da continuidade de docentes que estiveram presentes na instituição em anos anteriores e continuam perpetuando os princípios pedagógicos originários do programa. Assim, analisando o breve histórico, fica evidente que ainda antes da chegada da pandemia da Covid-19, a instituição, seus docentes e discentes já estavam lidando com questões delicadas e se adaptando a uma nova realidade colocada à instituição nos últimos anos.

Em março de 2020, quando foi deflagrada a interrupção das atividades presenciais como medida de proteção contra a disseminação do Coronavírus, a comunidade escolar do Cicalt começou a vivenciar um período mais intenso de preocupações. Durante aproximadamente um mês, não se sabia o que aconteceria com os cursos, se seriam descontinuados ou se seria feita alguma proposta de ensino alternativa. No mês de abril, a SEE-MG comunicou que as atividades escolares teriam continuidade de forma remota e, para tanto, instaurou o Regime Especial de Atividades Não Presenciais (REANP) a ser seguido por toda a rede estadual de ensino. Uma das principais ferramentas do REANP é o Plano de Estudos Tutorados $(\mathrm{PET})^{3}$ que se trata de uma apostila virtual, inicialmente com periodicidade mensal $^{4}$, com orientações, conteúdos e atividades, para que estudantes continuassem seus estudos. O PET pode ser entregue a estudantes de forma impressa caso seja necessário, mas no Cicalt, por exemplo, nem sempre foi possível entregar a todas as pessoas que apresentavam a demanda devido a

${ }^{3}$ Para mais informações sobre o REANP e o PET, acesse: https://www2.educacao.mg.gov.br/.

4 A partir de 2021, os PET’s passaram a ter periodicidade bimestral. 
questões logísticas, como um sistema de distribuição por vezes ineficaz, falta de recursos financeiros, etc.

O PET foi destinado a todas as etapas e categorias de formação que a SEEMG compreende: educação infantil, ensino básico (ensino fundamental e médio) e ensino técnico profissionalizante. No entanto, os PET's da educação infantil e do ensino básico são formulados por uma equipe pedagógica da SEE-MG, enquanto os PET's de cursos técnicos profissionalizantes, como são os do Cicalt, devem ser elaborados pelas professoras e professores responsáveis pelas disciplinas, assim, cada disciplina tem o seu próprio PET. No caso dos cursos técnicos do Cicalt, que são constituídos por três semestres letivos que se configuram como três módulos interdependentes, há seis disciplinas em cada módulo, de forma tal, em 2020, somavam-se então seis PET's por mês a serem realizados e entregues por estudantes.

Nesse momento, a comunidade escolar mostrou grande resistência ao formato decretado. No âmbito do curso de teatro, alguns dos questionamentos foram: como a formação em teatro poderia ser conduzida via PET? Como substituir o convívio e o espaço compartilhado da sala de aula por uma apostila? Como manter os valores pedagógicos de liberdade e emancipação nesse modelo de ensino? As respostas para essas perguntas não mostravam traço de esperança em um momento inicial. Muitas e muitos estudantes infelizmente se distanciaram dos cursos por não concordarem com o formato ou por não terem condições psicológicas ou materiais para continuarem da maneira proposta pela SEE-MG, já que era minimamente necessário um aparelho com conexão à internet para acessar o PET virtual, algo que parte do corpo discente não dispunha, e o PET impresso não era uma alternativa completamente garantida.

De acordo com Merisio et al (2018) a estrutura escolar tende a reproduzir mecanismos didático-pedagógicos de ordem e disciplinamento, que perpetuam o plano de poder de governantes e não apresentam espaço para a expressão de singularidades e subjetividades de estudantes. Nessa direção, o PET pode ser considerado um mecanismo dessa natureza, já que, ainda que tenha sido elaborado como medida temporária, de um ensino emergencial, ele não apresenta porosidade suficiente para absorver especificidades pedagógicas e dialogar com 
as multiplicidades de contextos escolares e estudantis de todo o estado de Minas Gerais, mesmo que os conteúdos sejam modificados de acordo com a etapa e categoria de ensino. Ou seja, o PET é um documento de caráter prescritivo e normativo baseado no antigo formato tradicionalista de pergunta e resposta e avaliação quantitativista que proporciona uma relação de ensino-aprendizagem burocrática, conteudista e esvaziada de sentidos.

Considerando as adequações que o Cicalt já havia passado devido à sua agregação à SEE-MG, o PET pode ser observado como mais um dos diferentes mecanismos de normatização e uniformização impelidos sobre a instituição de ensino sem levar em consideração suas especificidades. Nesse sentido, como espaço histórico de resistência a esses modelos, seria necessário que o Cicalt encontrasse formas alternativas de rachar a estrutura do PET, de tensionar o seu sistema e propor estratégias outras de ensino-aprendizagem. É importante frisar que não havia a possibilidade de não adotar o PET, como ferramenta regulamentar do ensino emergencial em Minas Gerais, todas as escolas públicas ligadas à SEEMG devem empregá-lo obrigatoriamente, assim, o desafio da equipe docente do curso de teatro consistiu em criar um espaço além do PET, uma espécie de antiestrutura. De acordo com Machado (2015), a antiestrutura, no âmbito do ensino do teatro, pode ser entendida como um sistema latente de caminhos potenciais que se distanciam da ordem e equilíbrio da estrutura normativa, que prevê troca horizontal entre docentes e discentes a partir de sua presentificação e participação ativa nos processos.

Tratando-se aqui de contexto específico da formação teatral, é importante refletir-se também sobre a sua natureza convivial e relacional, absolutamente incompatível com as circunstâncias sanitárias atuais. Para estudantes de um curso de teatro, o teatro é vigorosamente necessário, mas quando a vida é atravessada por um vírus altamente transmissível com risco letal, o teatro como se conhece, como lugar de contato e coabitação, ganha posição na prateleira, sem previsão da próxima data de uso. Então,

Quanto tempo se pode esperar pelo teatro quando ele falta? Questão importante hoje em dia: pode ser que se tenha necessidade de teatro e ele não esteja à disposição. Ou, pelo menos, não o teatro de que se 
necessita. O teatro disponível não é necessariamente aquele que a vida pede - certas necessidades permanecem insatisfeitas. Inquietude de vida e de morte. Em caso de necessidade, se o teatro falta, nos falta, e se a carência persiste, algo corre o risco de morrer. "Nós" não morreremos, claro que não. Encontram-se substitutos. Mas algo em nós pode morrer. O quê? A exigência que sustenta a reflexão aqui apresentada, não é, portanto, a de preservar, conservar "o teatro" a qualquer preço: é possível conservar múmias, cadáveres. Perguntamo-nos, se uma vida, e que tipo de vida, quer (eventualmente) o teatro. E como, se ele lhe faz falta, esta falta pode ser satisfeita (Guénoun, 2004, p. 16).

Assim, na falta e na necessidade pelo teatro, buscando manter "esse algo" vivo em si e tecendo opções pedagógicas alternativas e complementares ao PET, docentes e discentes do curso iniciaram um levantamento sobre as possibilidades de investigação da linguagem teatral no contexto de isolamento devido à Covid19. Se o "teatro convencional" - presencial - não estava disponível no momento e a proposta de ensino remoto da própria escola não atendia às demandas da formação teatral, quais caminhos poderiam ser seguidos? De que forma os processos de ensino-aprendizagem em teatro poderiam coexistir e resistir à pandemia? Como o teatro poderia ser um mobilizador de fissuras na estrutura de ensino do PET? Como criar antiestruturas para ensinar e aprender teatro em tempos pandêmicos?

\section{Fazer teatro sem fazer teatro}

No contexto escolar relatado, havia cinco turmas de teatro em andamento, sendo duas delas em processo de finalização do curso técnico - as primeiras turmas da história do Cicalt a concluírem a recém inaugurada modalidade técnica. O terceiro e último módulo do curso prevê um processo de criação, que resulta em um produto cênico a ser compartilhado com a comunidade escolar, e que já estava em andamento desde novembro de 2019, porém, a chegada da pandemia interrompeu o desenvolvimento das criações das turmas concluintes sem deixar perspectivas.

Quando foi iniciado o período de isolamento social, docentes e discentes do curso de teatro do Cicalt passaram a realizar encontros virtuais semanais por meio de chamadas de vídeo coletivas. Vale ressaltar que os encontros virtuais não eram 
previstos como método de ensino pela SEE-MG até esse momento ${ }^{5}$, assim, a equipe do curso de teatro do Cicalt foi realizando-as de forma autônoma. Mesmo no período em que ainda não se sabia ao certo como se daria a continuidade ou não dos estudos, procurava-se manter tais encontros com o intuito de conservar o vínculo e criar um espaço de descompressão, de aliviamento para tantas questões, ansiedades e incertezas provocadas pelo contexto da pandemia. Nessa altura, os encontros eram preenchidos por conversas e desabafos em sua maioria e, até então, não eram realizados exercícios ou experimentos teatrais. Com a chegada do PET como plataforma de estudo remoto, entendeu-se que os encontros virtuais seriam ainda mais necessários diante de todas as insatisfações que causou entre estudantes. Dessa forma, as chamadas de vídeo passaram, pouco a pouco, a incluir assuntos que estavam presentes nos PET's, como uma possibilidade de relação e apreensão do conteúdo teatral para além dos limites da apostila.

À medida que as semanas foram passando, a relação com a virtualidade foi se tornando um pouco menos desconfortável e decidiu-se propor para as turmas do terceiro módulo que não fosse deixada de lado a sua montagem de formatura. Para tanto, seria preciso mergulhar nas possibilidades das plataformas virtuais, compreendendo como o teatro poderia ser ali inserido e vivenciado. Nesse sentido, visualizando uma rota de investigação coesa para o momento, o corpo docente responsável pelas atividades das turmas concluintes ${ }^{6}$ decidiu pautar as práticas investigativas que viriam a partir dali na noção de performatividade, diretamente associada aos modos do fazer artístico contemporâneo.

De acordo com Féral (2015), o surgimento da arte da performance redefiniu os parâmetros do fazer artístico como um todo a partir da década de 1970 e o campo teatral também foi influenciado pelas características e modos de criação de tal linguagem artística. Para a autora, "a noção de performance sublinha (ou quer sublinhar), o fim de um certo teatro, do teatro dramático particularmente e,

${ }^{5}$ A partir do ano de 2021, as chamadas de vídeo passaram a ser oficialmente consideradas como possibilidade de espaço para aulas complementares ao PET.

${ }^{6}$ O corpo docente foi composto por Júlia Camargos, autora do presente artigo, por Rainy Campos (atriz, diretora, produtora e professora de teatro), Lucas Fabrício (ator, diretor e professor de teatro) e Paulo Maffei (ator, diretor e professor de teatro) - todos artistas-docentes atuantes na cidade de Belo Horizonte. 
com ele, o fim do próprio conceito de teatro tal como praticado há algumas décadas" (2015, p. 116). Assim, a performatividade passou a ser um elemento essencial para analisar o teatro produzido em tempos contemporâneos. Ela pode apresentar dois eixos de definição, um diz respeito à performance como arte e outro da performance como experiência e o teatro atual evoca o cruzamento entre ambas as dimensões: uma mais ligada aos modos de criação artística caracterizada pela construção fragmentada e fluida de signos e sentidos, e a outra, associada à uma vivência em nível antropológico social e cultural (Féral, 2015).

Nesse sentido, os contextos de ensino e aprendizagem podem também assumir qualidades performativas, o que significa o estabelecimento do espaço educativo como um ambiente de invenção e criação, de tensionamento de estruturas pré-concebidas pela instituição escolar, envolvendo as subjetividades de discentes e docentes conjuntamente em processo de construção de conhecimento (Icle e Bonatto, 2017). Ou seja,

\begin{abstract}
A noção de performance não se limita a acontecimentos artísticos. [...] Assim, a potência da noção de performance no campo da educação, em especial na análise da escola, circunscreve-se [...] também na proposição (pedagogias performativas), pois a qualidade da performance (o performativo) é a capacidade que ela tem de nos mostrar a transformação como fator essencial da ação humana: na performance fazemos alguma coisa que nos permite refazer-nos a nós mesmos (Icle e Bonatto, 2017).
\end{abstract}

Assim, com base na noção da performatividade, as professoras e professores foram conduzindo diferentes práticas criativas com estudantes através do Zoom, uma plataforma de conferência remota. Buscando a performatividade em nível artístico e estético, mas também como uma experiência, uma vivência compartilhada, que apontava caminhos para lidar de forma alternativa tanto com a realidade do ensino remoto, mas também com o dia-a-dia pandêmico. Dito de outra forma, a noção de performatividade como orientadora, permitiu que docentes e discentes refizessem a si, o seu fazer teatral e a sua prática de ensinoaprendizagem naquele momento.

Vale mencionar que, durante todo o processo de criação, docentes e discentes trabalharam conjuntamente, inclusive, além da função de orientação, as 
professoras e professores assumiram-se como atrizes e atores performers nos experimentos, jogando e atuando com estudantes, compreendendo que essa iniciativa seria um estímulo, um encorajamento para que as turmas imergissem na nova experiência. Como "estudantes-performers e professores-performers" (Icle e Bonatto, 2017), abriu-se em sua relação o espaço para a invenção de formas próprias de elaboração da conjuntura pandêmica e de criação a partir dela.

As práticas propostas compreendiam a utilização dos variados elementos que compõem a ação cênica: o corpo, a voz, o texto, o espaço, a iluminação, os adereços, etc., mas sempre considerando o ambiente virtual que se ocupava também como recurso de criação. Ou seja, as experimentações giraram em torno da relação com a câmera, considerando especialmente os aspectos da imagem em vídeo (cor, formas, distância, espacialidade e luz e sombra) e os aparatos de pesquisa que estudantes e docentes dispunham em suas próprias casas (cômodos, objetos e até pessoas). As turmas trabalharam também com dramaturgias performativas próprias, escritas por estudantes, que foram adicionadas ao trabalho com o vídeo simultaneamente às experimentações no Zoom ou por meio de gravações que receberam tratamento de edição de áudio e foram adicionadas ao trabalho com vídeo posteriormente. Além disso, as ferramentas do Zoom foram observadas e manipuladas como dispositivos de criação, as formas de ajuste de vídeo e áudio, os cenários virtuais, a opção de gravação, a organização dos "quadradinhos" de participantes da chamada na tela e o bate-papo foram se tornando plataformas dramatúrgicas e linguagem estética.

No que diz respeito à temática, ambas as turmas do terceiro módulo optaram por abordar os atravessamentos provocados pela pandemia, cada uma à sua maneira. O trabalho da turma da noite foi intitulado "Exercícios para dias estranhos"7 e o mote de criação foi a investigação da estranheza presente nos dias pandêmicos que passavam. Alguns dos elementos que inspiraram e preencheram as ações performativas de estudantes dessa turma foram a solidão, a saudade, a desesperança, a morte e o tédio, este último com uma participação especial, pois ao ser vivenciado e compartilhado, possibilitou a criação de uma camada de humor e deboche que se tornou uma marca do experimento cênico virtual. Cabe dizer 
que, essa marca humorística abriu espaço inclusive para a construção de críticas ao momento experienciado no contexto brasileiro.
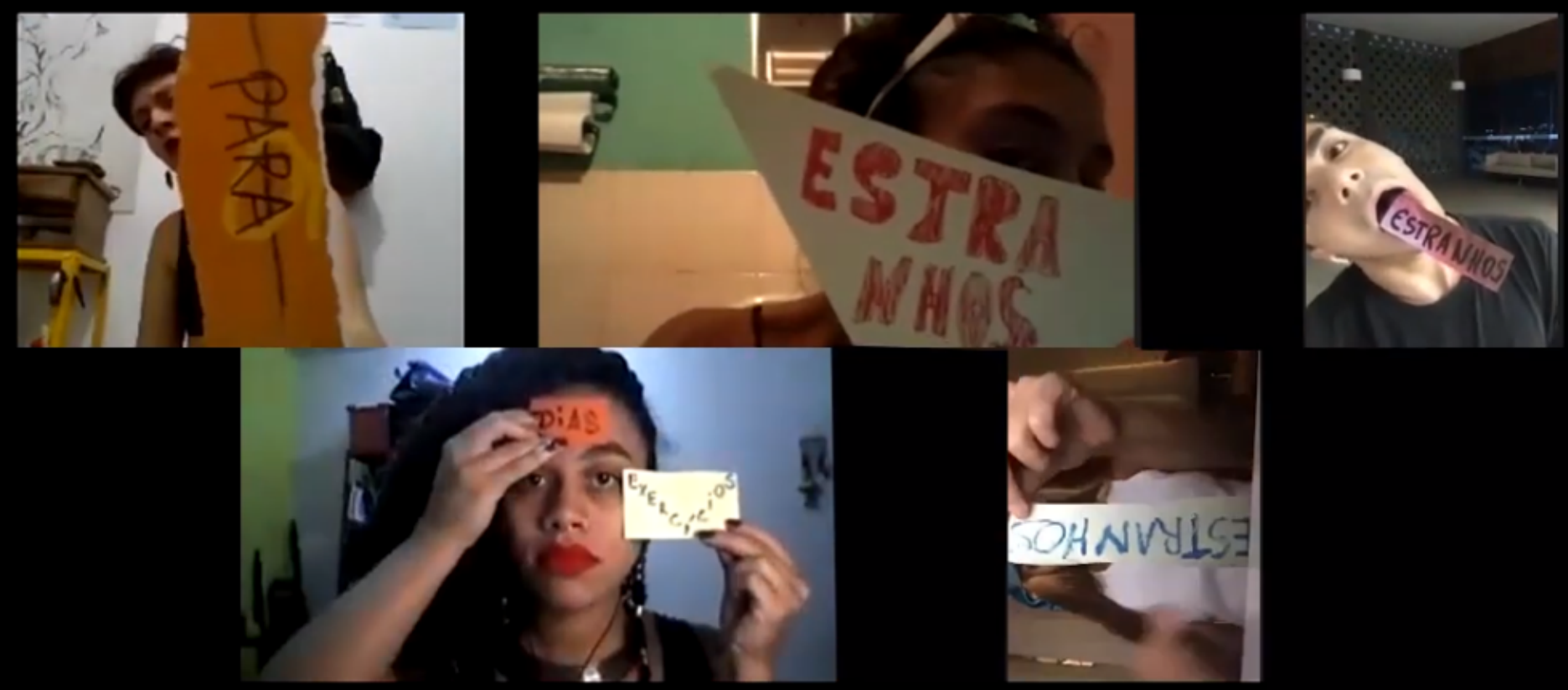

Fonte: Print do vídeo disponível em https://youtu.be/oTFqh6ovlT4

Já o trabalho da turma da tarde intitulado "Casa adentro", teve como foco central a exploração dos espaços das próprias casas de estudantes e docentes como lugar de performatividade. Abordou-se as formas de habitar a casa e o próprio corpo, refletindo sobre os efeitos que o isolamento social pode provocar e sobre os diferentes sentidos que a ideia de confinamento gerava. Dessa forma, a proposta foi baseada na exploração de elementos a princípio cotidianos, de uma maneira alternativa, extraordinária. Os percursos pela casa, as receitas culinárias e ações simples como deitar, escovar os dentes, tomar um copo d'água ou dar

${ }^{8}$ Vídeo completo do experimento disponível em: https://youtu.be/qTzSTbdOE 0. 
descarga foram ganhando camadas poéticas. Um elemento bastante presente nesse trabalho foi a reflexão sobre a monotonia e a repetição de dias que parecem os mesmos, que começam mais uma vez, sem perspectiva de alteração.

Figura 2 - Experimento cênico virtual "Casa adentro"
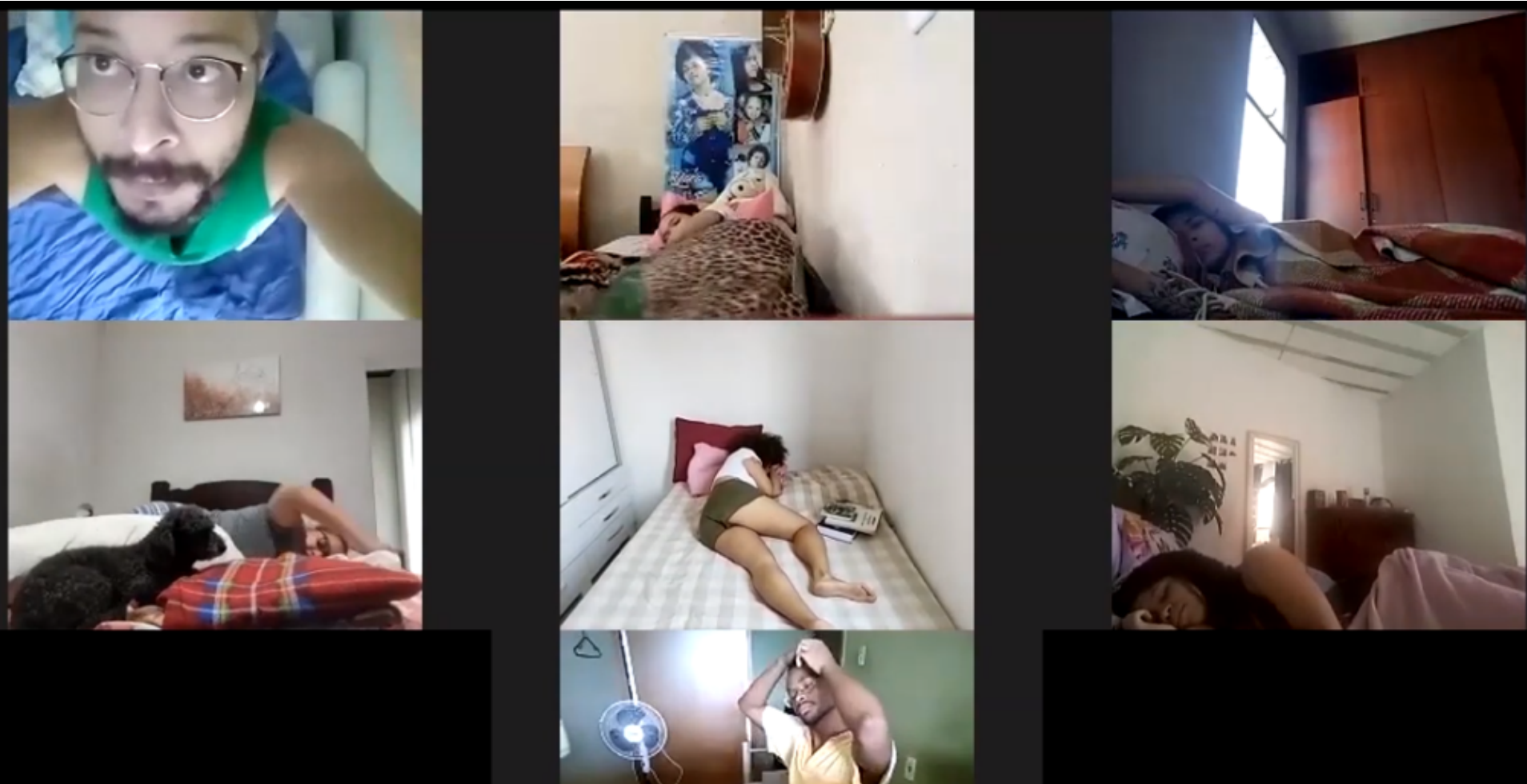

Os diferentes experimentos vivenciados com as turmas foram gravados a partir da plataforma Zoom e a última etapa do trabalho foi a edição de vídeo que, a princípio, pode parecer distante do universo teatral, mas que posteriormente veio a revelar algumas aproximações. Quando já havia gravações suficientes de cada turma de suas investigações cênico virtuais, o corpo docente teve reuniões para debater sobre o material levantado e decidir quais caminhos a edição de vídeo poderia seguir para costurar as ações e cenas performativas desenvolvidas nos trabalhos. Assim, logo estabeleceu-se uma relação entre a edição de vídeo e 
o trabalho dramatúrgico e a direção, ou seja, a organização dos materiais audiovisuais capturados não se tratava de mero arranjo de aparência, mas a maneira como seriam organizados definiria a narrativa que se desejava propor. Assim, compreendendo a edição de vídeo como um processo dramatúrgico e de direção, o corpo docente foi capaz de elaborar o discurso, o dizer de cada experimento realizado.

Deste modo, é possível considerar que os trabalhos da turma da tarde e da noite perpassaram pelo questionamento comum sobre os limites e definições de teatro. Ao ocupar um espaço talvez nunca imaginado antes para produzir teatro, as turmas tensionaram as fronteiras dessa linguagem artística na prática. Em “Exercícios para dias estranhos", essa reflexão se explicita em uma frase que se apresenta repetidamente: fazer teatro sem fazer teatro. Parece impossível a princípio, mas a única forma de realizar algo que é e não é o algo original, é ampliando as suas possibilidades. O corpo docente empregou os termos telatralidades e performavirtualidades para nomear o que as turmas produziram criativamente, pois os elementos misturados que formam tais palavras inventadas estavam todos presentes, a tela, a virtualidade, mas também as teatralidades e as performatividades.

Além da pesquisa artística influenciada por aspectos da performance, é essencial frisar como a noção de performatividade foi essencial para inspirar as ações em nível pedagógico e relacional. Nesse sentido, pode-se observar a iniciativa da equipe do curso de teatro como uma tentativa de criar uma alternativa ao aparato de ensino remoto imposto. As videochamadas foram espaço de resistência do convívio, mesmo que virtual, algo que apenas as páginas dos PET's, sejam virtuais ou impressas, não possibilitariam. Ademais, ao longo dos processos criativos, foram sendo construídas lacunas por entre os “dias estranhos", para manter relações com pessoas e atividades que ajudavam a suportá-los, a ressignificá-los.

\section{Reflexões finais}

Quando transcorriam ainda os primeiros meses de pandemia e artistas da 
cena começaram a ocupar os ambientes virtuais para dar continuidade a seus trabalhos, vários questionamentos pipocaram entre a classe teatral: Afinal, existe teatro online? Será que isso é teatro? Deve-se adaptar o fazer teatral ao "novo normal virtual" ou defender a sua essência convivial? A importância dessas perguntas não está localizada no estabelecimento de respostas definitivas, mas na inquietude e remelexo que elas provocam, no movimento que elas incitam sobre artistas do teatro a continuarem pensando, criando e inventando outras formas para o seu fazer. Esse movimento tem relação com o desejo, que mesmo em circunstâncias adversas, parece sobreviver, ou pelo menos, parece querer sobreviver. Talvez seja o desejo, aquilo que Guénoun (2004), ao refletir sobre a necessidade do teatro, afirma que não deve morrer.

Desde que começamos o isolamento social, ao participar de experimentos cênicos digitais e, também, pensar e realizar experimentos artísticos-pedagógicos, sempre me vinha à cabeça o texto de Gertrude Stein: "queria que isto fosse uma peça"... e eu sempre completava com "queria que isso fosse teatro"... Porque, para mim, é isso que ela estava dizendo: "Transforme essa dramaturgia impossível em teatro" e eu olho ao redor e vejo artistas e professores de teatro "buscando meios de transformar essa realidade impossível em teatro". Queria que fosse teatro... Esse querer, a meu ver, está no campo do desejo, e desejo é composto de uma rede de movimentos e forças. Tenho pensado, neste momento, que esses diversos experimentos se encontram no campo do desejo, "desejos de teatro". Acredito que primeiramente por um desejo de criação, de experimentação, mas também de sobrevivência, de gerar renda, de inventar possibilidades - teatro para mim sempre foi invenção, tem que ser invenção (Maffei, 2020, n/p).

Assim, no curso de teatro do Cicalt, a partir do desejo de teatro, mesmo em um contexto hostil, impulsionou-se ações a partir da noção de performatividade que permitiram a criação de antiestruturas em diferentes dimensões: na dimensão artística e estética, na dimensão relacional e subjetiva de participantes que ali refletiram sobre si e sobre o momento vivenciado e na dimensão de ensinoaprendizagem por propor uma estratégia de ensino alternativa e suplementar àquela decretada pela SEE-MG.

Certamente a pandemia, quando finalizada, vai deixar consequências e modificações para os contextos escolares e teatrais. Não é possível dizer que foi inventado um novo teatro ou uma nova pedagogia teatral, mas certamente, os 
atravessamentos da virtualidade marcarão a história e os fazeres artísticopedagógicos a partir daqui. Ao menos, a busca por fissuras e antiestruturas no cotidiano pandêmico pela performatividade seguramente deixará marcas nos sujeitos criadores e participantes das experiencias aqui relatadas.

Por fim, é importante registrar que uma parte considerável de estudantes não pôde acompanhar os processos criativos por se encontrarem em situações de vulnerabilidade social, material ou psicológica. Os experimentos aqui apresentados foram possíveis para aquelas pessoas que, de alguma forma, dispunham de aparatos tecnológicos, o que não condiz com a realidade de todo o corpo discente do Cicalt. Além disso, há estudantes que nem conseguiram realizar o isolamento social recomendado pela necessidade de continuar trabalhando presencialmente pela sua subsistência, o que muitas vezes, impossibilitava a sua participação nos encontros criativos por questões logísticas ou até de esgotamento físico e mental. Esse dado revela que as estratégias de ensino, mesmo com todos os esforços pedagógicos e humanos do corpo docente, não abarcam todos os contextos de vida de estudantes. Apesar de o momento da pandemia ser delicado e exigir iniciativas rápidas para a educação, é preciso refletir sempre e continuadamente sobre pedagogias não excludentes, que enxergam educandas e educandos como seres integrais e plurais, preocupando-se com a construção de um conhecimento que possa fazer sentido na sua vida cotidiana.

\section{Referências}

GUÉNOUN, Denis. O teatro é necessário? São Paulo: Perspectiva, 2004.

FÉRAL, Josette. Além dos limites: teoria e prática do teatro. São Paulo: Perspectiva, 2015.

ICLE, Gilberto, BONATTO, Mônica Torres. Por uma pedagogia performativa: a escola como entrelugar para professores-performers e estudantes-performers. Cadernos Cedes, São Paulo, v. 37, n. 101, p. 7-28, 2017

MACHADO, Marina Marcondes. Só rodapés: Um glossário de trinta termos definidos na espiral de minha poética própria. Rascunhos, Uberlândia, v. 2, n. 1, p. 53-67, 2015. Disponível em: http://www.seer.ufu.br/index.php/rascunhos/article/view/28813/17060. 
Acesso em: 13 jun. 2021.

MAFFEl, Paulo. Desejos de teatro. Blog Mistura Teatro, produção e memória. Belo Horizonte, n. 54, 2020. Disponível em:

https://www.misturateatro.com/post/desejos-de-teatro. Acesso em: 13 jun. 2021.

MERISIO, Paulo, ARAúJO, Getúlio Góis de, SILVA, Ligia da Cruz. Experiências cênicas: fissuras criativas na escola com crianças e adolescentes. Urdimento Revista de Estudos em Artes Cênicas, Florianópolis, v.3, n.36, p. 181-203, 2019. Disponível em:

https://www.revistas.udesc.br/index.php/urdimento/article/view/15731/10879. Acesso em: 10 jun. 2021.

PAULA, Júlia Camargos de. Teatro que fica: sentidos atribuídos por jovens à sua experiência de formação teatral. 2020. Dissertação (Mestrado em Educação) Faculdade de Educação - Universidade Federal de Minas Gerais, Belo Horizonte, 2020. 